Fecha de recepción: diciembre 2017 Fecha de aceptación: marzo 2018 Versión final: julio 2019

\section{Mapuche terrorista. Pervivencia de estereotipos del siglo XIX en la construcción de la imagen del "indio" como otro/extranjero en la coyuntura de la Argentina actual.}

Carina Circosta *

\begin{abstract}
Resumen: La imagen del "indio" salvaje e incivilizado configurada por los artistas viajeros desde el siglo XVI, fue continuada por los discursos del siglo XIX y se consolidaron con la llamada "generación del ' 80 " por ser útil a sus objetivos de neo-colonización territorial hacia el interior del país.

En este artículo se busca evidenciar que, junto al hostigamiento y persecución del sector mapuche, que toma trascendencia a partir de la muerte de Santiago Maldonado, se reflotan aquellas estigmatizaciones ahora fuertemente dimensionadas y distorsionadas por los medios masivos de comunicación; focalizando la otredad en la imagen del mapuche extranjero-separatista-terrorista, activando rasgos discriminatorios.
\end{abstract}

Palabras clave: pueblos originarios - otredad - mapuche - estereotipo.

[Resúmenes en inglés y portugués en las páginas 201-202]

${ }^{(*)}$ Lic. y Prof. en Artes (UBA), Mgter. en Estudios Latinoamericanos (CEL-UNSAM), Doctoranda en Artes, (UBA). Docente en "Historia del arte precolombino" y "Sociología y antropología del arte" en la carrera de Artes de la Universidad de Buenos Aires; y en "Historia del arte europeo y latinoamericano del siglo XIX" en el Dto. de Artes Visuales de la Universidad Nacional del arte. Investigadora Formada en diferentes proyectos UBACyT, UBANEX y UNA. Actualmente es co- directora del proyecto "Imagen e imaginario sobre el sector indígena en el discurso político argentino. Desde el siglo XIX a la coyuntura actual” (UNA).

El término "indio" surge del error. Así fueron nombrados los habitantes de estas tierras cuando Colón cree haber arribado a las Indias, y es por ello que, como plantea Bonfil Batalla (1992), se trata de un término que se acuñó junto y desde el discurso colonizador, llevando a la homogeneización de una gran cantidad de etnias existentes en la América Antigua - Abya Yala. Además de ser un concepto que no reconoce la diversidad de las culturas preexistentes, ni las distinciones jerárquicas de las personas, al aplicarse indiscriminadamente, el término "indio" denota el orden de subordinación que deviene de con la conquista, organizando al mundo entre colonizadores y colonizados. Las imágenes que 
producen los europeos sobre la población americana dan cuenta de tal des-clasificación, ya que de acuerdo a su imaginario, se identificó a los hombres de estas tierras como seres caníbales, cinocéfalos (hombres con cabeza de perro), sátiros, cíclopes, panoicos (hipertrofia de algún órgano), blemmias (hombres con la cabeza en el pecho) y gigantes pataco$n^{1}{ }^{1}$. Este proceso es estudiado por Beatriz Pastor para dar cuenta de la profunda deformación de la realidad que conlleva el relato de Colón, planteando que la "ficcionalización" del indígena se genera en un mundo que empieza a regirse con nuevas pautas económicas, con fines estrictamente comerciales, en donde

...los tres primeros rasgos de caracterización de los indígenas (...)-desnudez, pobreza y falta de armas- los definían como salvajes y ciervos (...) el cuarto rasgo -la generosidad- los califica como bestias, por incapacidad de comerciar de acuerdo con las leyes de intercambio del mundo comercial (citada por Gómez Moraina, 1993, p. 69-70).

Se presentan aquí dos ejes que regirán el estereotipo indígena: salvajismo/incivilización e ingenuidad/inocencia que se conformarán visualmente en torno a las ideas de "salvaje" y "buen salvaje".

Durante las primeras décadas del 1800 América se ve sacudida por las revoluciones independentistas que ponen fin al período colonial y da inicio a las formaciones de las naciones republicanas. En la Argentina, el proyecto de los "hombres de mayo" exhortan por una sociedad sin jerarquías y la inclusión de los pueblos originarios en la construcción nacional, pero las políticas de los sucesivos gobiernos perjudicaron la situación indígena, volviendo a ser sometidos y se invisibilizados como agentes sociales. La codificación racial que distingue primitivo-sometido-inferior/civilizado-dominante-superior, continúa finalizada la colonia; dando forma a un patrón de poder que Aníbal Quijano (2000) define como "colonialidad", ya que la dominación colonial, racial y eurocéntrica, siguió vigente y diseñó el plano político, económico, epistemológico y estético. Este proceso implica que la occidentalización y la racialidad continúan aun derrotada la colonia porque "...la estructura social de las naciones recién inauguradas conservó, en términos generales, el mismo orden interno instaurado durante los tres siglos anteriores, $y$, en consecuencia, los indios continuaron como una categoría social que denota al sector dominado" (Bonfil Batalla, 1992, p. 38). En el plano cultural, Colombres (1993) refiere a la ambigüedad des-colonizadora, ya que cuando se produce el alejamiento con España -ahora sinónimo de atraso y dominación- se produce el acercamiento a la cultura francesa que se ha hegemonizado como el equivalente al progreso y la civilización, acepando así la ubicación periférica con respecto a la modernidad dominante. Este proceso es claro para la Argentina que dando la espalda a toda la tradición artística (indígena y colonial) se mira de manera especular con la cultura occidental, sin realizar, como plantea Adolfo Colombres (1993), ningún proceso de ajuste ni apropiación. Artistas mestizos formados en la tradición plástica local-colonial y producciones indígenas valoradas como artesanías, no ocuparon ningún espacio en la tradición que se construye excluyéndolos del relato histórico canónico, ya que afiliado con las Bellas Artes se busca compensar esa "...falta de tradición artística americana” (Amigo, 1994) estableciendo una continuidad con la herencia europea. 
Paralelamente el sector indígena queda invisibilizado y oculto por medio de los discursos y políticas raciales y eurocéntricas que no permiten pensarlos como sujeto de producción, devenidos una vez más en el "otro" cultural, objeto a ser representado. Al respecto, Burke plantea la existencia de dos posturas en la representación de la distancia cultural, una negadora, que asimila a

...los otros a nosotros (...) mediante la utilización de la analogía, tanto si el empleo de esta es consciente o inconsciente (...) La segunda respuesta habitual es justamente la contraria de la anterior. Consiste en la invención consciente o inconsciente de otra cultura opuesta a la propia. De este modo, convertimos en "otros" a nuestros congéneres (Burke, 2005, p. 155-156).

Ambas posturas, que para nuestro caso podemos entender en términos del "buen salvaje" o "bárbaro sanguinario", implican una re-presentación que oculta o tergiversa las cualidades propias de los indígenas, al mismo tiempo que acuña una relación de poder.

En el territorio argentino fueron los artistas viajeros que llegaron de diferentes partes del viejo continente los que fueron construyendo una iconografía sobre el indígena que es vulgarmente asumida como documento histórico sin atender a que "...el (...) "estereotipo" (...) al igual que la palabra "clise" (...) puede no ser completamente falso, pero a menudo exagera determinados elementos de la realidad y omite otros" (Burke, 2005, p. 158). Esa iconografía sentó para la conformación del "costumbrismo" o "tipicismo", el género pictórico más característico del siglo XIX, generando una gran cantidad de imágenes en las que podemos detectar los dos mecanismos descriptos por Burke en tanto la representación del "otro" cultural. Por un lado, el "buen salvaje" como el otro asimilado, podemos registrarlo en las piezas litográficas de la década del '20 como las del marino inglés Emeric Essex Vidal y las del ingeniero saboyano Carlos Enrique Pellegrini, así como los grabados de la década del 30 de Alcides D’orbigny y Emile LaSalle de 1837, e incluso en obras de Carlos Morel (Figura 1), un artista argentino que recupera esos modelos al formarse en base a la tradición artística europea. En todos estos casos se remarcan los aspectos benevolentes que coinciden con los valores de quienes lo representan: los indígenas se presentan posando mansos y estáticos, conforman un núcleo familiar unicelular, producen lo que consumen o venden sus excedentes, tienen cuerpos esbeltos y armónicos con proporciones ideales y bellas, etc. Como contrapartida, encontramos las pinturas y grabados que demonizan al "indio" a partir de dos tópicos recurrentes en la historia visual decimonónica: las escenas de malones y cautivas. Mauricio Rugendas, artista alemán que experimenta una larga estadía latinoamericana, plasmó en sus obras una serie imágenes que contribuyen a la conformación del estereotipo del indio salvaje y peligroso (Figura 2). Aunque recurre a escenas imaginadas o tomadas de algunas otras obras literarias ${ }^{2}$, interesan porque han dado sustento al imaginario que existía en la sociedad, en el que se concebía al indígena como un bárbaro, una amenaza y estorbo para el proyecto nacionalmoderno (Gallardo Porras, 2012, p. 83) 

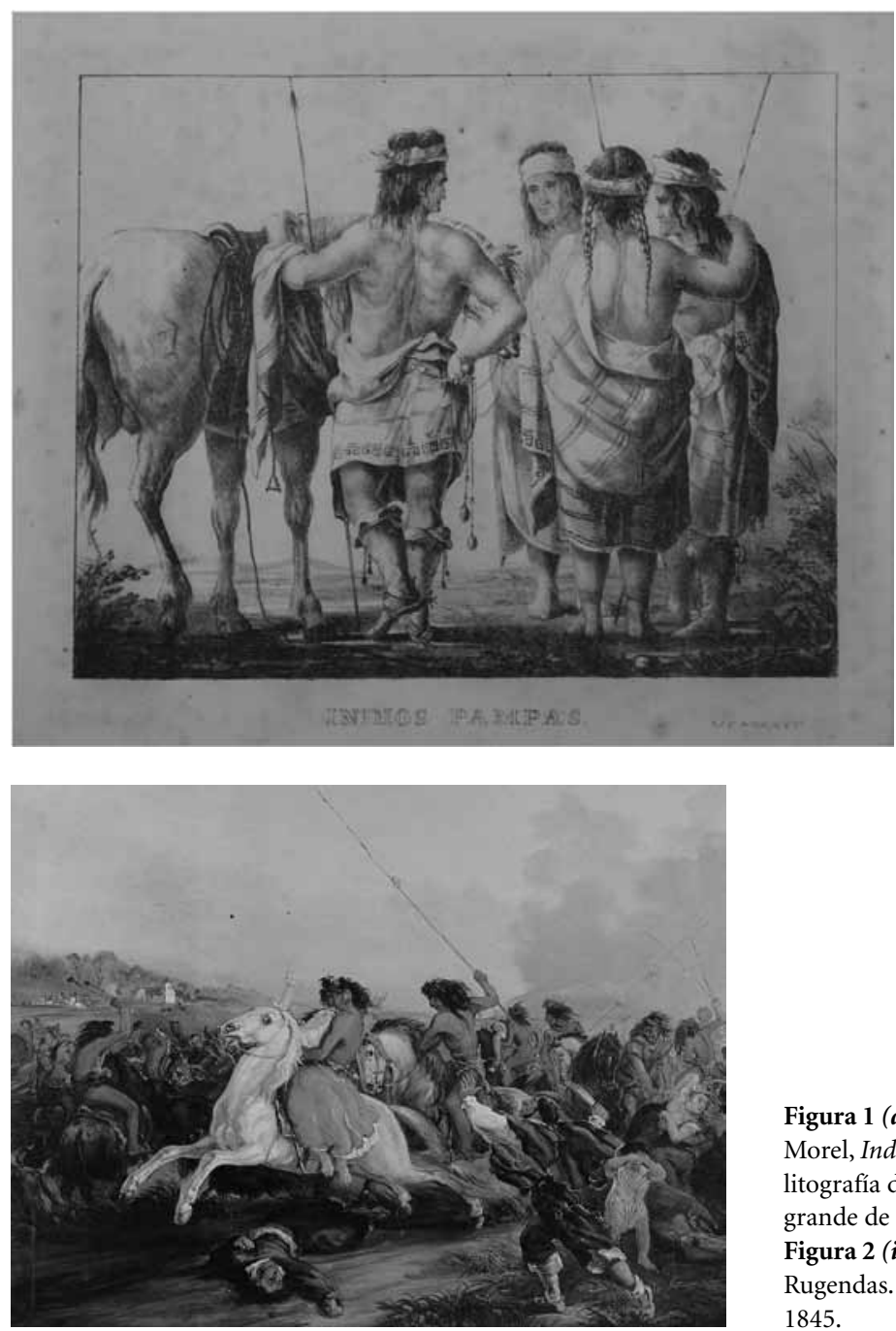

Figura 1 (arriba). Carlos Morel, Indios pampas, litografía de la Serie grande de Ibarra, 1841. Figura 2 (izq.). Mauricio Rugendas. El malón. Óleo, 1845 .

Así se apuntalaron los prejuicios y estereotipos que siguieron vigentes sobre los pueblos originarios y sus descendientes como símbolos del atraso y la incivilización, a la par que el gaucho fue ganando terreno como sinécdoque de la identidad nacional. Los discursos literarios y visuales jugaron aquí un rol fundamental, ya que son elementos decisivos para crear el basamento de la "ficcionalidad" que implica lograr una id-entificación que aglu- 
tine a “...todos los súbditos de un Estado [para que puedan] reconocerse simbólicamente en una cultura, una lengua y una tradición histórica comunes (además de coexistir físicamente en un territorio muchas veces artificialmente delimitado)" (Grüner 2004, p. 63). En este relato, Prilidiano Pueyrredón, considerado uno de los primeros artistas argentinos por haberse formado académicamente en Río de Janeiro y Francia y famoso por realizar los retratos de las personalidades de la alta sociedad a la que él mismo pertenecía. Abordó también la pintura costumbrista en la que las que cristalizó una iconografía nacional en donde opera un proceso de tradición selectiva condensando ciertas figuras devenidas sinécdoques de la "argentinidad": la pampa, el ombú y el gaucho con sus costumbres. Las imágenes costumbristas de Pueyrredón acompañan el discurso triunfante de Bartolomé Mitre, que tras la batalla de Pavón dio inicio a la etapa de reconstrucción nacional inaugurando una política de perfil liberal que se va a consolidar con la generación del 80, junto con la centralizalización del proyecto nacional en la zona pampeana. Las imágenes acompañan discriminación en la que se excluyen los lindes internos ${ }^{3}$, minimizando la gran diversidad de etnias, prácticas culturales y paisajes que convivían en el vasto territorio argentino, dando cuenta de que “...la construcción de la nacionalidad fue en la Argentina un proyecto de la clase dirigente, por un lado tendiente a homogeneizar y controlar a sectores populares con distintas tradiciones, históricas y valores y por otro orientado hacia su propia legitimación" (Amigo, 1994, p. 316). Pueyrredón nos muestra en "El rodeo" de 1861, la convivencia armoniosa de los distintos sectores sociales en las estancias: el patrón citadino, y el gaucho ya domesticado que actúa como capataz o peón según su rango, son partes constitutivas de una nación en crecimiento que aceptan mansamente el rol que por su etnia deben ocupar, el indígena se presenta ausente en esta célula de producción.

Esta misma organización se establecía en el diseño para el frontis de la catedral que el escultor francés Joseph Douburdieu proyectó para la Catedral metropolitana. A pesar de que nunca fue realizado ${ }^{4}$, sus imágenes demuestran el lugar que se le otorgaba al sector indígena en el proyecto nacional (Figura 3). El siguiente comentario realizado por Pellegrini en 1853 es elocuente:

...en medio (...) está la Religión (...) A la izquierda (...) la Verdad (...) A su derecha la Inmortalidad (...) De ambos lados del trono (...) la Fe y la Esperanza (...) una multitud de indígenas que corren presurosos a recibir el pan de vida eterna (...) masa de seres primitivos e inocentes que marchan sobre la vía del verdadero progreso, sigue el ángel que los custodia, cuya flameante espada los separa de los idólatras, quienes abatidos ocupan con sus fetiches un lugar bien apropiado a su miseria (...) En cuanto a los personajes que llenan la otra parte del tímpano, se presenta el genio de la Historia (...) nuestra joven América (...) En pos de la América vienen varias clases de nuestra sociedad obsequiando a la Madre de la Patria: el militar, su espada; el artista, su pincel; el filósofo, su saber; la industria, sus prodigios (citado por Payró, 1971, p. 18-19).

El espacio marginal que el escultor le otorga a los originarios en la composición y la adjetivación negativa que les confiere en el comentario: primitivos, inocentes, idólatras, miserables, se condice con el lugar social que autoriza la élite gobernante: vencidos por la 


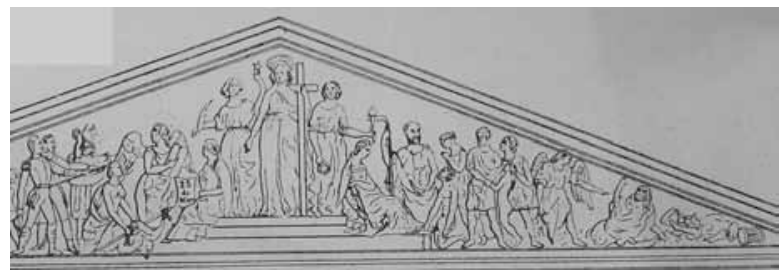

Figura 3. Joseph

Douburdieu. Proyectó

para frontis de la

Catedral, 1853

religión católica y las normas republicanas ocupan el sitio de su miseria, no tienen nada para ofrecer a la joven nación. Mientras tanto, el gaucho y la pampa devienen el epicentro visual - ideológico - económico del proyecto de país agro-exportador que se buscaba consolidar y para ello es necesario "liberar" las tierras de las comunidades preexistentes, generando un proceso de conquista interna del centro-sur del territorio que se consagró con la llamada "Campaña del desierto" realizada entre 1878 y 1879; un plan sistemático de dominio y destrucción que dejó el resultado de miles de originarios muertos, otros tantos desaparecidos y esclavizados. En este sentido es que entendemos, junto con Grüner, que la configuración de las identidades nacionales es una "... necesidad "burguesa" estrechamente vinculada a la construcción moderna de los estados nacionales, en el contexto del emergente modo de producción capitalista" (Grüner, 2004, p. 59).

El proyecto neo-liberal que ocupa el gobierno desde 2015 puso en escena una serie de acciones y discursos que nos permite evidenciar su filiación con el legado de fines del siglo XIX. Con respecto al sector indígena y a la manera en que se piensa la conformación de la identidad argentina, nos encontramos en un plano occidentalizante y represivo, donde los recursos lingüísticos y visuales utilizados nos demuestra cómo se vuelven a activar ciertos estereotipos conformados en el siglo XIX que buscan instalar en el sentido común de la población la figura de la peligrosidad del sector indígena. Nos interesa particularmente, contextualizar el discurso neo-colonialista o de colonialidad en la que se enmarcan los discursos y las acciones de la clase dirigente, para entender la significación que adquieren aquellos estereotipos del "indio salvaje y atrasado", que además de mostrarse solventes todavía en gran parte de la población, ahora se potencian por el impacto masivo que logra la difusión de imágenes en los medios masivos de comunicación hegemónico.

Reseñar los fundamentos y las acciones políticas del gobierno actual sobrepasa los límites de este escrito, nos basta con señalar que en esta etapa de capitalismo global las medidas económicas liberales llevan a generar beneficios concentrados en el sector empresarial trasnacionalizado, incentivando a ciertos sectores que perjudican directamente a las comunidades originarias. Obviamente que se trata de una situación que ya se venía ejecutando, lo que marca aquí la diferencia es que se evidencia el apoyo económico y político a estos grupos poderosos, que el gobierno acompaña con medidas de opresión y persecución a las comunidades que se manifiestan de manera contraria. Podemos anotar en este sentido las medidas adoptadas en favor del sector agropecuario concentrado 
casi exclusivamente a la producción sojera, que demanda grandes extensiones territoriales impidiendo el desarrollo de otro tipo de productos y lleva a que los pequeños productores prefieran arrendar sus haciendas antes de cultivarlas. Mientras que se recupera la sinécdoque "Argentina ES el campo" el gobierno aggiorna la vieja imagen decimonónica de "Argentina como granero del mundo" ahora devenida "el supermercado del mundo". Junto al monocultivo, la industria forestal y la mega-minería, son dos grandes amenazas para las comunidades originarias que luchan por mantener sus territorios y su soberanía alimentaria y cultural. A este panorama se suma otro gran problema: la enorme posesión de territorio nacional en manos extranjeras que buscan controlar y explotar recursos naturales inconmensurables. Y este punto es esencial en nuestro caso porque el recrudecimiento de la violencia hacia el pueblo mapuche que vivenciamos en esta coyuntura, es una fase más del largo conflicto que este sector entabla con el Estado y particulares en torno a la problemática de la recuperación del territorio.

En el plano simbólico el gobierno maneja una suerte de doble discurso o ambigüedad que distancia las “puestas en escena” de las "acciones políticas". Nos referimos, por ejemplo, a la reunión que, en su campaña electoral, en noviembre de 2015, el actual presidente tuviera con líder Qom Félix Díaz que acampaba en la Av. 9 de Julio para visibilizar una serie de demandas que eran desatendidas por el gobierno que ejercía el poder en ese momento; el candidato se comprometió a atender y dar solución a sus peticiones, pero, al momento actual, la situación, lejos de remediarse se ha agravado, como lo denuncia el mismo dirigente indígena. Asimismo, podemos entender como performances sin sentido su participación en el ritual de ofrenda a la Madre Tierra realizada como acto de cierre de campaña el 19 de noviembre de 2015 en la Quebrada de Humahuaca, que ha replicado en sucesivas celebraciones del "Día de la Pachamanca" en agosto de 2017 y 2018 en Jujuy.

Entendemos que se trata de "gestos"-"fotos"-"posturas políticamente correctas", si las consideramos a la luz de los hechos y dichos que el equipo de gobierno ejecuta, ya que se contradice con otros los discursos en los que se apela a la construcción de lo identitario nacional, donde claramente el sector indígena no es parte constitutiva. En este sentido es contundente la postura del presidente Macri cuando sostuvo en el Foro Económico Mundial de Davos de 2018, como "natural” la unión entre el Mercosur y la Unión Europea ya que en Sudamérica "todos somos descendientes de europeos" (Pagina 12, 25-1-18). La revitalización del imaginario de la identidad argentina blanca y europea y la búsqueda de consolidar el libre comercio con Europa ofreciendo al conjunto mundial un país proveedor de alimentos, resuenan como ecos decimonónicos; pero contrastan ahora con otros hechos de nuestra historia más reciente. En las últimas décadas se vienen produciendo un fuerte proceso de organización indígena, que si bien es dispar en sus líneas ideológicas, confluyen con las voluntades de otros interlocutores no -indígenas que buscan reconfigurar el relato histórico echando luz sobre evidencia que fue invisibilizada por la historia oficial ${ }^{5}$. Las contradicciones que genera la figura del Pte. Roca, pendulando entre el genocida y el gran homenajeado por la historia, y las lecturas críticas sobre de la "Campaña del desierto", son tópicos muy fuertes de revisión y cuestionamiento. En este marco, la conmemoración del "Bicentenario de la patria" en 2010 mostró la diversidad de agrupaciones indígenas que funcionan independientemente de los órganos estatales, colectivos que tienen filiaciones políticas diversas y a partir de ello se marcan las distancias en su accionar, 
algunas accedieron al diálogo y firmas de acuerdo con el gobierno nacional de turno, otras optaron por armar un evento paralelo denominado "El otro Cententenario, el Centenario de los pueblos" ${ }^{6}$. No obstante, la caravana de comunidades Originariass que llegaron a la capital del país inauguraron el discurso con una frase que figuraba la imagen inversa a la que enarbola el actual presidente: "los argentinos no descendemos de los barcos, sino de los cerros, las montañas y los ríos" (Circosta, 2010).

Entendemos que la coyuntura actual es parte de una historia de eterna tensión que ahora se característica por la restauración de una política racista/occidentalista que podemos leer en términos de Quijano, cuando refiere a la colonialidad como un patrón de poder que tienen raíz colonial y se continua más allá de la colonización. Ese pensamiento eurocentrista que acompañó la conformación del Estado Nacional a fines del siglo XIX se continua en el actual panorama de

...globalización (...) [como] la culminación de un proceso que comenzó con la constitución de América y la del capitalismo colonial/moderno y eurocentrado. Uno de los ejes fundamentales de ese patrón de poder es la clasificación social de la población mundial sobre la idea de raza, una construcción mental que expresa la experiencia básica de la dominación colonial y que desde entonces permea las dimensiones más importantes del poder mundial (...) Implica, en consecuencia, un elemento de colonialidad en el patrón de poder hoy mundialmente hegemónico (Quijano, 2004, p. 248).

La ilustración local de este proceso la pudimos ver cuando en torno a la celebración del Bicentenario de la Independencia nacional, el presidente narró que habían reflexionado con su equipo de gobierno sobre "la angustia que debieron sentir los patriotas de 1816 cuando tomaron la decisión de independizarse de la colonia española” (Portal de Noticias, 10-072016), pensamiento que fue dirigido al invitado principal del acto, Juan Carlos de Borbón, emérito Rey de España, al que se refirió como "Querido Rey", recolectando una oleada de críticas y refutaciones documentales. Unos meses antes, desde la cartera económica, el ministro le había pedido disculpas a España por los perjuicios causados a sus intereses financieros ante las políticas proteccionistas del anterior gobierno.

El marcado sesgo de colonialidad se evidencia también en la manera en que los funcionarios del gobierno refieren a las personas indígenas y a los procesos históricos. Vale como ejemplo los dichos Esteban Bulrich, quien en 2016 cuando ocupaba el cargo de Ministro de Educación de la Nación sostuvo que “...no hay independencia sin educación y tratando de pensar en el futuro [estaban haciendo] la nueva Campaña del Desierto, pero no con la espada sino con la educación" (La Nación, 16-9-2016). Frase obscena que no sólo reivindica el genocidio, sino que desnuda el perfil elitista que profesan como casta gobernante, restaurando el binomio alta cultura-civilización del siglo XIX.

Con este discurso impregnado de radicalidad se vanagloria de conquista interna y se posiciona a los indígenas como otro cultural-enemigo-externo, y en este contexto se inserta el recrudecimiento de la violencia contra el pueblo mapuche. Tomando como referencia sólo el caso del $\mathrm{Pu}$ Lof de Cushamen, una comuna de la provincia de Chubut que se encuentra desde 2015 en un proceso de recuperación territorial mapuche, nos proponemos 
señalar la manera en que se recupera el constructo visual del siglo XIX, asumiendo junto con Malvestitti y Delrio

...la capacidad performativa tanto del estereotipo del indígena malonero como el discurso de la guerra ganada para construir excepciones. El efecto representacional de esta categoría y discurso es el de la minimización (por ser pocos, de otro lado, en definitiva, de otro Estado, y por ser inferiores) de los sujetos colectivos que engloba (Malvestitti y Delrio, 2018, p. 48).

Y si bien los autores realizan este análisis en torno a los resultados de la Campaña del Desierto, nos interesa señalar justamente la continuidad y pervivencia de ciertos tópicos que se activan en la coyuntura actual, donde se repara en la idea de minoría salvaje/violenta - enemigo interno/terrorista - extranjeros/marginal - atrasado/anacrónico. Los autores enumeran al museo (de ciencias naturales y artístico), el manual de lengua y la colección folclórica, como los mecanismos que permitieron esas configuraciones. Nos permitimos plantear que el rol de los medios de comunicación hegemónicos se suma aquí como fuerte dispositivo de difusión de aquellos valores construidos en el siglo XIX que ahora se refuerzan y re-contextualizan según los problemas e intereses epocales, buscando cristalizar un cierto significado en las subjetividades y en el sentido común de la población.

Resulta pertinente a nuestros propósitos el análisis que Azocar Avedaño y Flores Chávez realizan al respecto de las fotografías de mapuches de Chile porque podemos hacerlo extensivo a nuestro caso. Los autores plantean la imposibilidad de enunciación de los pueblos originarios desactivados como sujetos productores para devenir en objetos que se re-presentan según los intereses de las clases dominantes. Así diferencian los diferentes estereotipos que se configuraron según el momento histórico: "desde la llegada de los españoles y hasta mediados de siglo [XIX] (...) [como] gente que vivía permanentemente en armas defendiendo su libertad, como guerreros invencibles, símbolo de valentía y heroísmo. A partir de la derrota de los españoles (...) década del 50 (...) se muestra a un "araucano" que ya no realiza acciones valientes sino bestiales; ya no estamos frente a guerreros sino a bandidos (...) a partir de la ocupación definitiva de la Araucanía y el inicio del proceso reduccional, la imagen del indio bárbaro, sanguinario y cruel es reemplazada por el indio flojo y borracho (...) la sociedad necesita de un discurso que explique la situación de pobreza y marginalidad en que se encuentran los mapuche. Una manera de escapar a la responsabilidad, es explicarla a partir de la ignorancia, la flojera y alcoholismo de los indígenas y no como producto de la reducción de sus tierras y la ruptura de su sistema económicos, político, social y cultural" (Azocar y Flores, 2000 p. 69). Dos grandes obras canónicas de la historia del arte argentino son ejemplos claros de esta configuración: "Ocupación militar del Rio Negro en la expedición al mando de Julio A. Roca" del artista Uruguayo Juan Manuel Blanes, realizada entre 1878-9 y "La vuelta del malón” de Ángel Della Valle, de 1892.

En la primera, conocida como "La campaña del desierto", se construye una narrativa verosímil que busca naturalizar de manera celebratoria la feroz embestida genocida que el Estado realiza entre 1878 y 1885 . El grupo de indígenas se ve derrotado, sentados en el piso en el margen izquierdo, secundados por un obispo y vigilados por un ejército moderno 


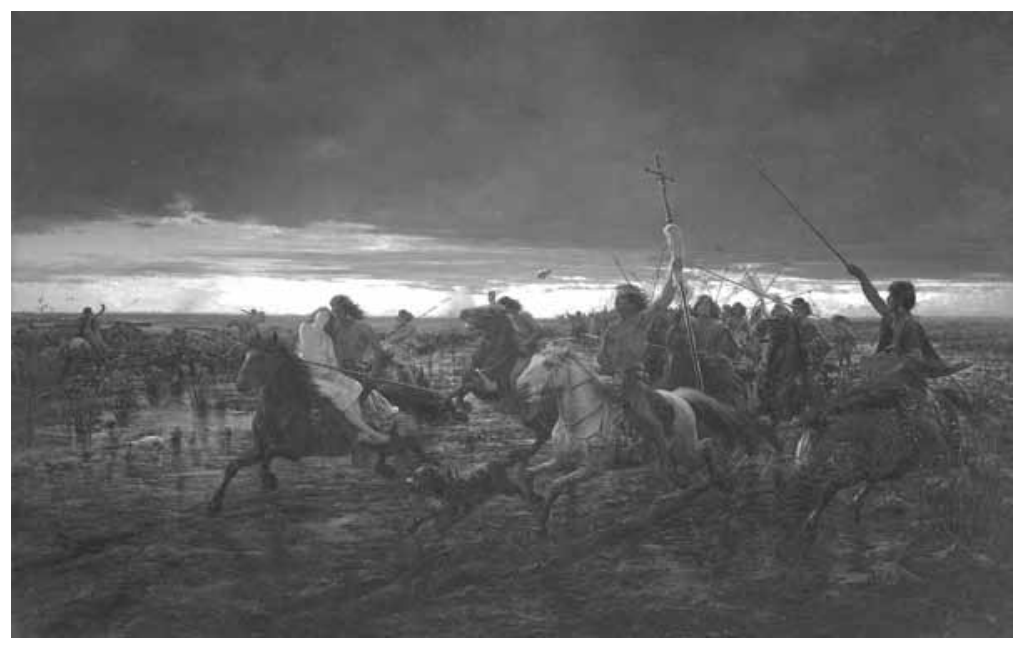

Figura 4. Angel Della Valle. La vuelta del malón, 1892.

y ordenado que los ha doblegado; los científicos-agrimensores representan el sector civil que acompañó el ataque (Amigo, 1994). Blanes los muestra vencidos y Della Valle retoma el tópico del salvajismo, pero ahora el motivo costumbrista del malón deviene en pintura histórica (Figura 4). El cuadro, que ostenta un tamaño que era solo designado a la pintura de género conmemorativo es pintado en 1892, momento en que los malones eran ya cosa del pasado debido al debilitamiento y destrucción de las comunidades. La retórica de su discurso destaca los "atributos" de la "barbarie": la mujer cautiva, bienes materiales y los elementos robados de una iglesia,

...invirtiendo los temimos del mismo: no era el hombre blanco quien despojaba al indio de sus tierras, su libertad y hasta su vida, sino el indio quien robaba al blanco su más preciada pertenencia. La violencia ejercida por el indio sobre ella justificaría de por sí toda violencia contra el raptor (Malosetti Costa, 1997, p. 243).

Es elocuente la inversión en la significación que propone Malosetti haciendo énfasis en el poder de la enunciación y del enunciante, no es un dato menor la cercanía del autor a la clase terrateniente a la que su propia familia pertenecía, estableciéndose un "vínculo estrecho (...) orgánico cuando el artista proviene de la misma clase que representa (Gonzales, 2013, p. 103). Asimismo, podemos pensar que, si bien hemos señalado que en los últimos tiempos los pueblos originarios se han organizado y logrado una cierta visibilidad y revitalización en la procura de sus derechos, sus discursos son arrasados por las construc- 
ciones de sentido de los medios de comunicación hegemónica. Siendo estos últimos los mediadores de los intereses de las clases dominantes podemos hacer extensivo el análisis de Gonzales, en tanto

...los artistas [y los medios masivos de comunicación hegemónicos] como células vivas de la sociedad civil y de la sociedad política son parte de la ideología de la clase dominante más allá del tema u objeto representado en la obra, vigorizan la conciencia de su rol transformándola en una "concepción del mundo" que impregna todo el cuerpo social (Gonzales, 2013, p. 104).

Los medios hegemónicos reproducen los discursos de los funcionarios del gobierno construyendo un sentido que es muy difícil contrarrestar. No en vano una de las primeras medidas que ejecutó el equipo de gobierno fue la modificación por decreto de la Ley de Medios que había sido votada por unanimidad en el parlamento; restringiendo la expresión de las voces disidentes y debilitando el espacio de enunciación de las minorías, entre ellos, las comunidades indígenas.

En este contexto se suscitan los hechos que se generaron en el Pu Lof de Cushamen. Las tensiones generadas en el contexto de recuperación de territorio provocaron enfrentamientos con el Grupo italiano Benetton y se produjeron allanamientos, represiones a las manifestaciones y persecución política a los líderes de las comunidades, produciendo a su vez reacciones más radicales de los grupos indígenas que demandan el cumplimiento de la ley. La escalada de violencia llegó a picos máximos de tragedia en agosto de 2017 con la desaparición y muerte de Santiago Maldonado, un joven no-mapuche que solidarizado con la causa sufrió los procedimientos abusivos de las fuerzas de Gendarmería Nacional. Más tarde, se produjo el encarcelamiento y posterior extradición a Chile del lonko Facundo Jones Huala. Y si bien nos centramos en este caso, hay que considerar que no se trata de un hecho aislado, alcanza con mencionar que, en noviembre de 2017, en una represión de la Prefectura Naval Argentina a la Lof Lafken Winkul Mapu de Villa Mascardi de Rio Negro, se baleó por la espalda a Rafael Nahuel, un joven mapuche cuya muerte sigue impune a pesar de que su agresor fue identificado.

Fue justamente la repercusión mediática y la masiva manifestación de repudio de gran parte de la sociedad ante la desaparición de Maldonado la que logró la visibilización de la problemática de los indígenas del sur, pero rápidamente se instrumentó una impresionante campaña de criminalización de la comunidad mapuche. Al respecto tomamos las argumentaciones de la Ministra de Seguridad Patricia Bullrich como referente del discurso del Estado Nacional, que será reproducido y dimensionado por los medios masivos. Días después de la desaparición de Santiago Maldonado busca inculpar al sector mapuche y defender el accionar de la gendarmería sosteniendo que la represión fue una respuesta a

Una situación de mucha violencia, de gente que pasa todos los límites de los comportamientos democráticos, que utiliza cuchillos, armas, molotov, que rompe todo (...) no [permitiremos] que en la Argentina se asiente un grupo que utilice la violencia como forma de acción y quiera imponer una república autónoma y mapuche en el medio de la Argentina (La capital; 8-8-217). 
En otro momento esgrimió que: "Es un problema que tenemos los argentinos y tenemos que solucionar. Los argentinos y los mapuches" (El Destape, 16-8-2017). Se recurre en primer lugar al tópico que nos retrotrae a la aporía de la nacionalidad [chilena] del pueblo mapuche ${ }^{7}$, el mapuche no es argentino: quieren "imponer" una república dentro de este territorio, sostiene la ministra contradiciendo a la misma constitución argentina que en el artículo 75, inciso 17, de la reforma de 1994 "reconoce la preexistencia cultural y étnica de los pueblos originarios argentinos (...) la personería jurídica de sus comunidades, y la posesión y propiedad comunitarias de las tierras que tradicionalemente ocupan”. Es decir que los convierte en sujeto colectivo de derecho y obliga al Estado a regular el marco jurídico para garantizar protección y desarrollo para garantizar sus reivindicaciones históricas, cuestiones que obviamente no se cumplen.

Se recurre entonces a ciertas connotaciones ya instaladas en el sentido común de la sociedad: el sector indígena es violento, antes malonero, ahora terrorista. Los medios titulan las infundadas relaciones de la RAM (Resistencia Ancestral Mapuche) con grupos extremistas como las FARC, ETA, Sendero Luminoso, etc. que tienen una envergadura y organización que dista mucho de la infraestructura mapuche (Figura 5). Aquí es fundamental la relación texto/imagen, ya que el epígrafe (léase aquí título de la nota o zócalo del programa de televisión) funciona como anclaje de la imagen acotando el significado y orientando la "lectura" de la misma. Los dichos de los medios y actores políticos señalan la violencia de las comunidades, hablan de "protomontorismo", de grupos armados de gran envergadura, pero en las imágenes que se difunden sobresale la aparatosidad de las fuerzas policiales del Estado y el despliegue monumental de la Gendarmería que contrasta con el grupo minoritario de indígenas y el registro de armas secuestradas: palos, piedras y herramientas de trabajo (Figura 6). El sentido de la "violencia" se desplaza a los grupos indígenas pero las imágenes muestran la militarización del estado que los enfrenta, se recupera el tópico del indio malonero del siglo XIX cuando la imagen pivotea entre la peligrosidad y el miserabilismo, generando un efecto de enemigo -aniquilante/aniquilado. La tendenciosidad en la construcción de la noticia y de la representación del indígena devenido en "mapuche terrorista" se centraliza en la figura del encapuchado como la más recurrente para condensar ese sentido, representación que incluso llego al límite del cliché cuando un conductor se encapuchó para entrevistar en la tv a una persona mapuche (Figura 7$)^{8}$.

La criminalización implica además el cuestionamiento de la legitimidad de su identidad originaria, que se cristaliza sobre el estereotipo de la ancestralidad como retroceso, incivilización/anacronismo. Esos dos tópicos recurrentes: el atraso y el clishe indígena son esgrimidos también como discurso del gobierno y difundidos por los medios. Al respecto podemos tomar como ejemplo las palabras del diputado del PRO, Fernando Iglesias, cuando en torno al caso Maldonado plantea que le

...parece bien que les reconozcan un territorio a los mapuches con una condición: que vivan como sus ancestros, para preservar su cultura (...) Nada de celular, ni vacunas, ni heladeras. ¡A vivir en carpa, andar en bolas y cazar guanacos con boleadoras al grito de Abajo Occidente! (Info 135:2-10-2017). 

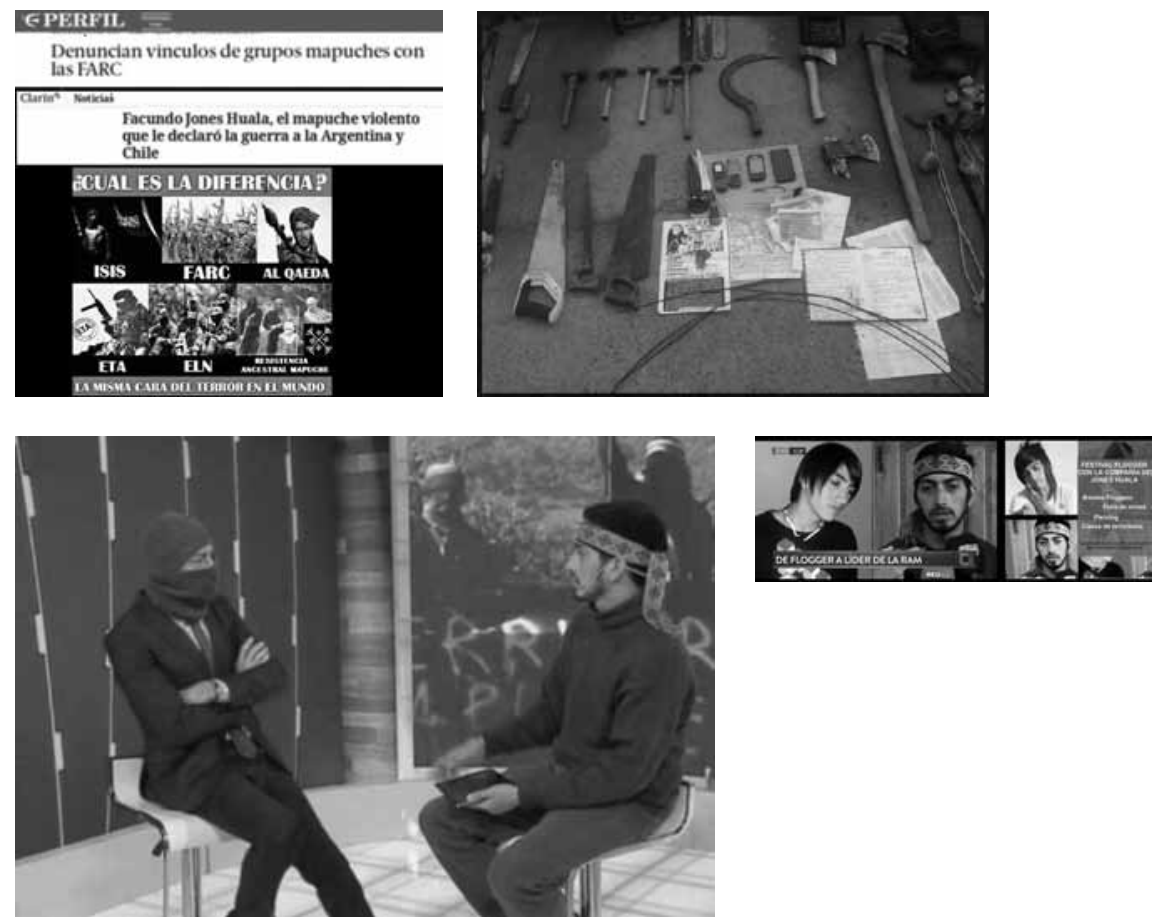

Figura 5 (arriba izq.). Titulares diarios Perfil (8-1-2017) y Clarín (21-1-2017). "Meme" de circulación en redes. Figura 6 (arriba der.). Fotografía publicada en Infobae (9-8-2017). Figura 7 (abajo izq.). Entrevista de Nicolás Repetto a Fernando Jones Huala, Telefe, 10-9- 2017. Figura 8 (abajo der.). Titular televisivo reproducido en Contexto (15-9-2017). "Meme" de circulación en redes.

Nos interesa resaltar los discursos de los dirigentes políticos porque son los que habilitan la proliferación de frases aberrantes, descalificadoras y xenófobas, que repercuten en los medios masivos por medio de informes y editoriales de prensa, llevando a que se multipliquen en las redes sociales. Aparecen entonces un sin fin de expresiones que cuestionan el uso de ciertas marcas de ropa o zapatillas o el acceso a la tecnología, recurriendo a la naturalización de la imagen indígena "atrasado" y "empobrecido" como resultado de su propia condición de miseria. La burla que recibió Fernando Jones Huala cuando los medios recuperan fotos de una etapa de su adolescencia en la que se acercó a la estética flogger (una de las tribus urbanas de principios del 2000) es otro claro ejemplo de la manera en que se busca cristalizar el estereotipo del indio-ancestral utilizado para cuestionar la legitimidad de su identidad étnica (Figura 8). Argumentos que no pueden sustentarse desde ningún enfoque socio-antropológico sobre la-s construcción-es de la-s identidad-es y que desco- 
nocen profundamente el proceso de re-construcción de la identidad originaria en países neo-post-colonizados como el nuestro (Grüner: 2002), se enraízan en los fundamentos más básicos del sentido común de gran parte de la población.

Es por ello que sostenemos que la pervivencia de aquellos tópicos estereotipantes del siglo XIX son congruentes con los intereses de este proyecto político de ideología neo-liberal. Tal vez, los dichos de los ministros Esteban y Patricia Bullrich resuenen con otra connotación si se contextualizan en sus antecedentes históricos. No es anecdótico que ambos comparten la descendencia de Adolfo Bullrich, dueño de la empresa inmobiliaria que se encargó del remate de las tierras sustraídas a las comunidades después de la "Campaña del desierto". En las palabras de los ministros se recupera el espíritu de los anhelos de Nación que Roca esperaba conformar, tal como lo expresaba en su discurso de asunción a la presidencia en 1880 :

Continuaré las operaciones militares (...) hasta completar el sometimiento de los indios (...) a fin de que no haya un solo palmo de tierra argentina que no se halle bajo la jurisdicción de las leyes de la nación (...) Libremos totalmente esos vastos y fértiles territorios de sus enemigos tradicionales, que desde la conquista fueron un dique al desenvolvimiento de nuestra riqueza pastoril; ofrezcamos garantías ciertas a la vida y la propiedad de los que vayan con su capital y con sus brazos a fecundarlos.

El discurso decimonónico se restaura a contrapelo de los procesos de reconstitución del indianismo y desentendiéndose de las nuevas concepciones de Estados plurinacionales que se experimentan en los últimos tiempos. La criminalización mapuche alienta el imaginario del indígena como enemigo interno (originario/extranjero devenido en terrorista), que atenta sobre una pureza imaginada. Así como en el siglo XIX, se busca instaurar un único discurso que focaliza en la condición étnica-política para legitimar la política de excepción que el Estado ejerce sobre ellos (Lenton y Delrío, 2018). No obstante, existen en el siglo XXI una serie de estrategias para la emisión de discursos resistentes a la dominación mediática-oficial, que, aunque adquieren escaso un peso relativo, abren la posibilidad de construcción de otro relato; la otra historia que merece ser contada.

\section{Notas}

1. Ver Sebastián, Santiago. (1992). Iconografía del indio americano. Siglos XVI-XVIII. Madrid: Ed. Tuero.

2. Gallardo Porras remite a La cautiva de Esteban Echeverría, Bs. As. 1837 y Viaje a Chile a través de los Andes de Schmidmeyer, Londres, 1842 con ilustraciones de Poeppig.

3. El término "linde" es acuñado por Eduardo Grüner (2002) como una suerte de traducción del In between conceptualizado por Homi Bhabha; una categoría que se diferencia del término "limite" para avanzar sobre el estudio de esas "fronteras porosas" que generan las tensiones en la dinámica de la conformación del sentido en las identidades nacionales. 
4. Los relieves del frontis que se encuentran actualmente fueron realizados en 1863 y se corresponden con el pasaje bíblico del "Encuentro de José y Jacob", adquiere una connotación política después del Pacto de San José de Flores (1853) que dispuso la incorporación de Buenos Aires a la Confederación Argentina.

5. En las últimas décadas se ha producido una importante bibliografía crítica sobre el proceso de organización nacional del siglo XIX y la "Campaña del desierto" y la forma en que estos episodios de la historia han sido des-aprendidos. Autores como Osvaldo Bayer, Marcelo Valco, Diana Lenton y Walter del Rio, son fuentes ineludibles. Asimismo, puede destacarse la política de restitución de huesos de los indígenas prisioneros-muertos que viene llevándose a cabo en el Museo de Ciencias Naturales de La Plata como un planteo a contrapelo del relato oficial de la historia argentina.

6. Ver Aranda, Darío. (2010) Argentina Originaria. Genocidios, Saqueos y Resistencias. Buenos Aires, La Vaca.

7. Un argumento que plantea Estanislao Zeballos en el siglo XIX, que se difunde en el siglo XX por autores como Rodolfo Casamiquela y ahora reflotado en los medios por el historiador Claudio Chávez.

8. Se trata del conductor Nicolás Repetto durante una entrevista a Fernando Jones Huala que se televisó por Telefe el 10 de septiembre de 2017.

\section{Referencias bibliográfcas:}

Azócar Avendaño, A. Y Flores Chávez, J. (2000). "Fotografía e imaginario sobre indígenas: dos miradas de los mapuches de la Araucanía a finales del siglo XIX”, en. Cuadernos del Sur. Historia. $\mathrm{N}^{\circ} 29$ Departamento de Humanidades, Universidad Nacional del Sur. Bahía Blanca.

Amigo, Roberto. (1994). "Imágenes para una Nación. Juan Manuel Blanes y la Pintura de Tema Histórico en la Argentina", en AA.VV. Arte, Historia e Identidad en América. Visiones comparativas. XVII Coloquio Internacional de Historia del Arte. Tomo II. México: UNAM.

Bonfil Batalla, Guillermo. (1992). "El concepto de indio en América: una categoría de la situación colonial" en AA.VV. Identidad y Pluralismo cultural en América Latina. Fondo Editorial del CEHASS. Editorial de Universidad de Puerto Rico.

Burke, Peter. (2005). Visto y no Visto. El Uso de la Imagen como Documento Histórico. Barcelona: Crítica.

Circosta Carina. (2010). "Repensar la argentinidad: visión, participación y acción de los pueblos originarios en los festejos por el bicentenario", en: Revista Lindes. Estudios Sociales del Arte y la Cultura. Año 1, No 1, diciembre, Buenos Aires. Disponible en www. revistalindes.org.ar

Colombres, Adolfo. (1993). "Modernidad dominante y modernidades periféricas, o el desafío de la nueva modernidad", en: América Latina: El desarrollo del tercer milenio. Buenos Aires: Ed. del Sol.

Gallardo Porras, Viviana. (2012). "Rugendas, artista viajero y su aporte a la construcción de la representación indígena”, en: Tiempo Histórico. $\mathrm{N}^{\circ} 4$. Santiago de Chile: Universidad Academia de Humanismo Cristiano. 
Gómez-Moriana, Antonio. (1993). “Cómo surge una instancia discursiva: Cristóbal Colón y la invención del indio”, en revista: Filología. Temas de la literatura española. Año XXVI, No 1-2. Buenos Aires: Facultad de Filosofía y Letras - UBA.

González, Florencia. (2013). "Fragmentos para una imagen argentina”, en Desajustes. Sobre Arte y Política en la Argentina. Paradiso: Buenos Aires.

Gruner, Eduardo. (2002) El fin de las pequeñas historias. De los estudios culturales al retorno (imposible) de lo trágico, Buenos Aires, Paidos.

Grüner, Eduardo. (2004). "El conflicto de la(s) identidad(es) y el debate de la representación. La relación entre la historia del arte y la crisis de lo político en una teoría crítica de la cultura", en Revista Facultad de Bellas Artes de la Universidad Nacional de La Plata , $\mathrm{n}^{\circ} 1$.

Lenton, Diana. "La criminalización de lo mapuche. EL NUEVO ENEMIGO INTERNO". En Aborigen Argentino. Agosto de 2017. Disponible en: http://www.aborigenargentino. com.ar/la-criminalizacion-los-mapuche-nuevo-enemigo-publico/

Malosetti Costa, Laura. (2001. “Buenos Aires-Chicago. La Vuelta del Malón”, en Los Primeros Modernos. Arte, Sociedad en Buenos Aires a fines del Siglo XIX. Bs. As: Fondo de Cultura Económica.

Malvestitti, M. y Delrio, W. (2018) “Memorias del Awkan”, en En el país del nomeacuerdo. Archivos y memorias del genocidio de Esado soble los pueblos originarios, 1870-1950". Buenos Aires, Ed. UNRN.

Payro, Julio. (1971). Prilidiano Pueyrredon, Joseph Dobourdie. La pirámide de mayo y la catedral de buenos aires. Buenos Aires: Facultad de filosofía y letras-UBA.

Quijano, Aníbal. (2000). “Colonialidad del Poder, Eurocentrismo y América Latina”, en E. Lander (Comp.) La Colonialidad del Saber: Eurocentrismo y ciencias sociales. Perspectivas latinoamericanas. Buenos Aires: CLACSO.

\section{Diarios y portales de noticias:}

Clarín. "Elecciones. Macri fue a la carpa qom de 9 de Julio y se reunión con Félix Días". 3-11-2015.

Clarín. "Rumbo al ballotage. Macri rindió culto a la Pachamama antes del cierre de campaña en Jujuy". 19-11-2015.

Contexto. "Payaso mapuche. Era flogger y ahora lidera a los terroristas RAM". 15-9-2017. https://www.contextotucuman.com/nota/91662/payaso-mapuche-era-flogger-y-ahoralidera-a-los-terroristas-ram.html. Acceso: 25-8-2018

El Destape. "El repudiable comentario de Bullrich: hablo de 'argentinos y mapuches". 16-8-2017.https://www.eldestapeweb.com/el-repudiable-comentario-bullrich-habloargentinos-y-mapuches-n32219. Acceso: 17-11-2018

El liberal Política. "Félix Días: 'teníamos expectativas con Macri pero las promesas se las llevó el viento"'. 8-1-2018. https://www.elliberal.com.ar/noticia/390020/teniamosexpectativas-macri-pero-promesas-se-llevo-viento. Acceso: 2-9-2018

El capital. “'No vamos a permitir una república mapuche en medio de la Argentina', advirtió Bullrich”. 8-8-2017.https://www.lacapital.com.ar/informacion-gral/no-vamos-permitir- 
una-republica-mapuche-medio-la-argentina-advirtio-bullrich-n1447849.html. Acceso: 4-9-2018

Infobae. "Fernando Jones Huala. De 'flogger' a líder mapuche": 2017. https://www.infobae. com/sociedad/2017/09/16/fernando-jones-huala-de-flogger-a-lider-mapuche/. Acceso: 25-8-2018

La Gaceta. "Bullrich sobre el conflicto con los mapuches: "estamos frente a grupos violentos que no respetan la ley”. 17-11-2017.https://www.lagaceta.com.ar/nota/753270/actualidad/ bullrich-sobre-conflicto-mapuches-estamos-frente-grupos-violentos-no-respetan-ley. html. Acceso: 2-9-2018.

La Nación. "Esteban Bullrich: 'esta es la nueva Campaña del desierto pero no con la espada sino con la educación"”. 16-7-2016.

La política on Line. "Hay tufillo a Sendero Luminoso". 24 de septiembre de 2018. https://www. lapoliticaonline.com/nota/108516-hay-tufillo-a-sendero-luminoso/. Acceso: 2-9-2 018.

Los Andes. "Macri dijo 'todos somos descendientes de europeos' y le llovieron las críticas". 25-1-2018. https://losandes.com.ar/article/view?slug=macri-dijo-que-todos-somosdescendientes-de-europeos-y-le-llovieron-las-criticas. Acceso: 21-9-2018

Página 12. "En Sudamérica todos somos descendientes de europeos”. 25 de enero de 2018. PDN Portal de Noticias. " 'Querido Rey'...una lamentable frase de Macri tiño de tristeza los festejos del 9 de julio". 10-07-2016. https://portaldenoticias.com.ar/2016/07/10/ querido-rey-una-lamentable-frase-de-macri-tino-de-tristeza-los-festejos-del-9-de-julio/. Acceso: 20-8-2018

Política Argentina. "El día que Macri descubrió a los indígenas" 5-11-2015. https://www. politicargentina.com/notas/201511/9506-el-dia-que-macri-descubrio-a-los-indigenas. html. Acceso: 28-7-2018

Política Argentina. "Macri justifico un acuerdo Mercosur-UE porque en 'América Latina somos todos hijos de europeos, principalmente". 6-7-2018. https://www.politicargentina. com/notas/201607/15154-macri-dijo-que-es-natural-un-acuerdo-mercosur-unioneuropea-porque-en-america-latina-somos-todos-hijos-de-europeos-principalmente. html. Acceso: 21-9-2018

\begin{abstract}
The image of the wild and uncivilized "indian" shaped by traveling artists since the XVI century, was continued by the discourses of the XIX century, that were consolidated with the so-called "generation of ' 80 ", for being useful to its objectives of territorial neo-colonization towards The inside of the country. The idea of the Mapuche-foreigner is thus constructed, marginalizing it from the ideology of national identity.

The dispute over the land was since then a never-ending battle intensified in the current conjuncture. This article seeks to show that, together with the harassment and persecution of the Mapuche sector, which takes on significance after the death of Santiago Maldonado, those stigmatizations that are now strongly dimensioned and distorted by the mass media are refloated; focusing otherness on the image of the foreign-separatist-terrorist Mapuche,
\end{abstract}


activating discriminatory features well installed in the common sense of a part of the population.

Keywords: native peobles - Otherness - mapuche - stereotype.

Resumo: A imagem do selvagem e incivilizado "índio" moldado pelos artistas viajantes desde o século XVI foi continuada pelos discursos do século XIX, que se consolidaram com a chamada "geração dos anos 80 ", por ser útil aos seus objetivos de neocolonização territorial em direção ao interior do país. A idéia do estrangeiro Mapuche é assim construída, marginalizando-o da ideologia da identidade nacional.

A disputa pela terra foi, desde então, uma batalha interminável intensificada na atual conjuntura. Este artigo procura mostrar que, juntamente com o assédio e a perseguição ao setor mapuche, que assume um significado após a morte de Santiago Maldonado, as estigmatizações que agora são fortemente dimensionadas e distorcidas pelos meios de comunicação de massa são reflutidas; focando a alteridade na imagem do mapuche-separatista-terrorista estrangeiro, ativando características discriminatórias bem instaladas no senso comum de uma parte da população.

Palavras chave: povos originários - alteridade - mapuche - estereótipo.

[Las traducciones de los abstracts fueron supervisadas por el autor de cada artículo] 